\title{
Toward the digital water age: Survey and case studies of Australian water utility smart-metering programs
}

\author{
Beal, C.D ${ }^{1}$, Flynn, $\mathrm{J}^{2}$ \\ ${ }^{1}$ Smart Water Research Centre and School of Engineering, Griffith University, Southport, Qld, 4222, Australia \\ ${ }^{2}$ Smart Water Research Centre, Griffith University, Southport, Qld 4222 and Joe Flynn \& Associates, South Australia
}

\section{Executive Summary}

The role of 'smart metering' in demand management, customer service, labor optimization, and operational efficiency is becoming increasingly recognized by Australian water utilities. The objectives of this paper are to provide a summary of the 2013 and 2014 surveys and in-depth interviews that were aimed at gauging the penetration of smart metering (SM) and intelligent water network (IWN) projects in Australian and New Zealand water utilities and to identify outputs and challenges faced subsequent to their implementation.

The key insights are summarized as follows:

- Smart meters and intelligent water networks are gaining momentum in Australasia, with at least 250,000 smart meters currently installed or planned for installation and $66 \%$ of the surveyed water businesses reporting projects underway or starting in the next 12 months.

- Key business drivers were easier to quantify and justify on water system economics rather than customer engagement and satisfaction. There appears to be a business case for deployment of smart metering technology, particularly for utilities seeking to avoid costs by lowering operating costs, reducing wholesale bulk water purchases, and/or deferring augmentation of infrastructure.

- Some utilities had well-advanced trials or operational rollouts, together with a similarly advanced understanding of the wider benefits of SM and IWN, while others were constrained by a lack of overall understanding and awareness of developing a business case, technology options, applications of data and the wider benefits of smart metering.

- Each water utility should know and understand its business drivers and goals. The value of smart metering and the specific business case drivers are highly contextual to location (e.g., opportunities for cost avoidance). The social benefits of customer satisfaction, community acceptance, and improved customer engagement and trust were major 'social' drivers.

- There is evidence that utilities are gaining an increased awareness of how digital metering and applying analytics of various data sets in near real-time, can benefit utility efficiency and customer service excellence. Aligned with data analytics was a clear focus towards the customer satisfaction (e.g. introducing web portals, leak alerts, two-way communications and customer consultation).

- In the last 12 months there has been a doubling in the number of utilities that are pursuing intelligent water networks - the integration of intelligent devices including water meters, pressure sensors, meter data, into all relevant business processes and systems and using this information to guide strategy and investment.

- As many respondents commented, there is an important need for an agreed upon and standardized set of definitions relating to smart-metering technology.

Keywords: big data, ICT, intelligent water network, smart water meter, water utility, survey research 


\section{Background}

There is a paradigm shift emerging in the ways water utilities view their customer relationships and interact with their water networks (Beal et al., 2014; Stewart. et al., 2013). Equally evolving, is the level of service that some customers expect from their water and energy utility, as well as the how and when water is used and how this usage is reflected in bills (Beal and Flynn, 2013). A variety of smart meter and communication networks are being installed in Australia with the clear purpose of addressing these needs, along with potential Capital Expenditure and Operating Expenditure savings that automated monitoring of water supply and demand can bring. A range of solutions are currently being pursued in Australia, and elsewhere, to manage and integrate meter data with existing core utility systems, and most importantly, how to extract value from the data, for both the utility and the customer (Beal et al. 2014, Stewart et al, 2010).

Collaboration and information sharing is not evident among Australian water businesses. Utilities are repeating previously held trials and investing in a variety of communication systems that have a range of network compatibilities and compliances with national standards. For example, communication systems can be either or one or two-way, they may or may not support open communication standards, and they may or may not comply with the Water Services Association of Australia (WSAA) smart-metering specification manual (WSAA 2010). Additionally, there appears to be little involvement or leveraging of non-water communications providers, such as electricity networks or the national broadband network (NBN), currently being rolled out. This fragmented and often ill-informed approach to adopting technologies for meeting the paradigm shift in the utility-customer interface, raises several critical questions. First, how well does this patchy rollout of smart meters reflect the substantial investment required? Second, how well understood by utilities already proceeding with a smart-meter rollout is the risk of technology redundancy, methods of risk mitigation, and data-integration strategies?

To answer these questions and address a plethora of design, technology, management, and implementation issues, a WSAA Roadmap (Figure 1) and Cost-Benefit Analysis model for smart metering and intelligent water networks were developed by the WSAA Metering Program Group in 2012. Building on these initiatives, the first WSAA Smart Metering and Intelligent Water Networks Seminar and Workshop, informed by a report on the state of smart water metering in Australia, was held in August 2013 to share information regarding the implementation and management of SM/IWN projects. A follow up survey and workshop in 2014 sought to build on the results of the 2013 survey. This paper presents a summary of the methods, results, and recommendations from the two surveys (including in-depth interviews), which were conducted by the Smart Water Research Centre (Beal and Flynn 2013, 2014). The purpose of the research was to assist the WSAA with the aim of gaining a deeper understanding of the state of smart metering in Australian water utilities.

The specific objectives of the research were to:

- Gauge the penetration of SM and IWN projects across Australian water businesses;

- Describe the 'who, how and why' of SM/IWN in Australian water businesses;

- Identify the key challenges typically faced in conducting SM/IWN projects;

- Undertake a Business Case Review of SM/IWN projects by the water utilities; and

- Collate and analyze information in a way that builds upon, rather than reinvents, the existing Roadmap and Cost-Benefit Analysis Framework developed by the WSAA smartmetering group in 2012. 


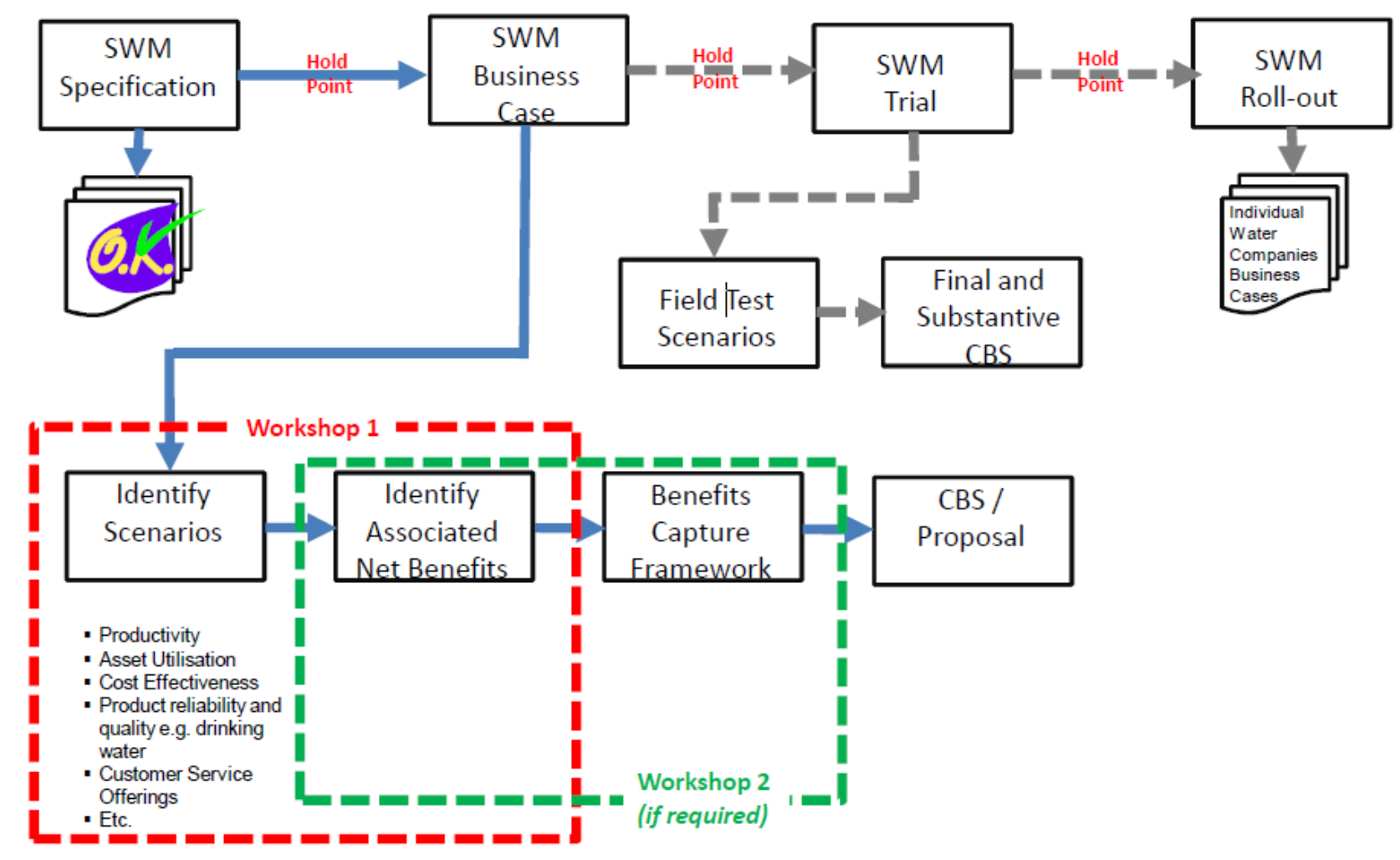

Figure 1. WSAA Metering Program Group Roadmap (2012)

\section{Methods}

\section{On-line survey}

Data were first gathered through an online survey tool specifically designed for the purpose of this study with guidance from the WSAA Smart Metering Program Group. Survey participants were recruited from registrants of the 2013 WSAA workshop. A link to the survey was automatically sent to each participant once they had officially registered for the workshop. This link accompanied an information letter that requested water business managers to take part in a 20minute online survey. The scope and purpose of the research was outlined, and a sample copy of a completed survey was provided to assist respondents in understanding of the nature of information that would be required.

In July and early August of 2013 and August 2014, the surveys were completed by 26 and 49 water businesses, respectively, across Australia and New Zealand. Collectively these businesses serve more than 6.5 million connected residential and commercial properties; although nonrandom and affected by self-selection bias, the sample covers about $50 \%$ of the Australian market and slightly less than $50 \%$ of the New Zealand market. The survey consisted of a combination of qualitative and quantitative questions, both open-ended and simple or multiple-choice (Figure 2).

The scope of the survey covered five main areas:

1. business case drivers and the benefits of smart metering projects;

2. general SM/IWN project details (number, starting date, cost, etc.);

3. technology used (communications, meter and data logger types, etc.);

4. utility-customer relationships; and

5. lessons learned (challenges and issues of design and implementation). 

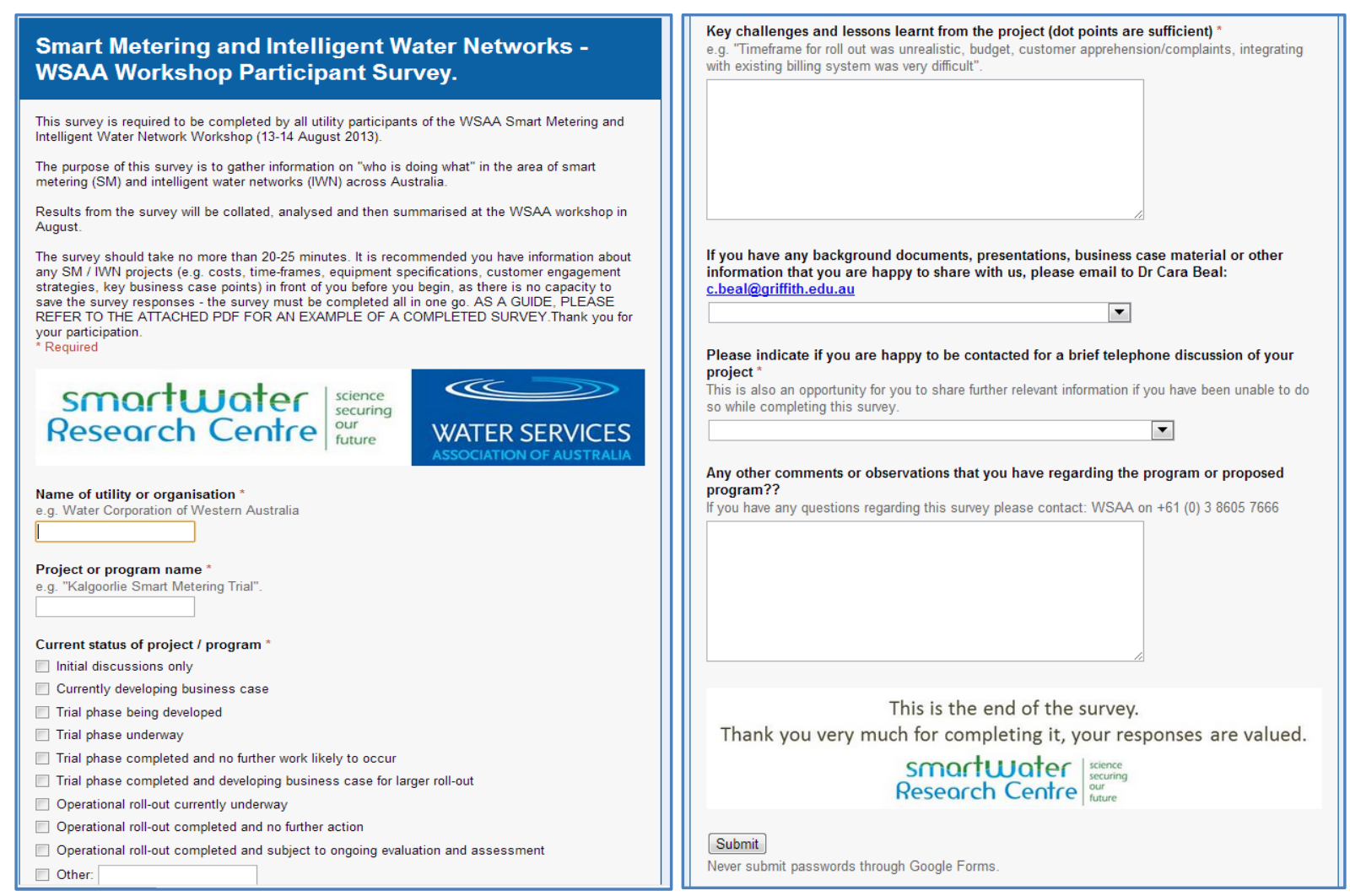

Figure 2. Snapshot of first and last page of the online survey form in 2013

\section{Targeted interviews}

Following an analysis of the online survey results, a subsequent detailed telephone interview was conducted with relevant personnel of those water businesses that had undergone significant effort in planning, implementing, and managing either pilot or main phase rollouts of SM/IWN projects. Four water businesses located in Western Australia, Queensland, Tasmania and Victoria were chosen in 2013, as they had sufficient experience and data to allow an in-depth examination. Along with follow-up interviews of the four businesses, a further nine were also interviewed in 2014. The telephone interview questions were designed to elicit real-world examples of cost savings, revenue increases, and customer benefits, all key factors that underpin the business case drivers for SM/IWN projects. Additionally, the telephone interviews sought to collate the lessons learnt from delivering the projects. Business-case concepts presented by Flynn and Little (2012) provided the prompting questions used to elicit relevant information.

\section{Definitions}

Although the WSAA had previously developed a set of terms relating to smart water metering, technology definitions were a point of ambiguity among respondents, as several responses suggested that a more standardized approach should be taken. Currently in Australia, the following definitions are recommended in the WSAA Smart Metering guidelines (WSAA 2010):

Automated meter reading (AMR): the automated collection of meter reads but still requiring a meter reader to visit the property or be nearby.

Advanced metering infrastructure (AMI): installation of fixed wireless collection network and the backhaul of metering data to a metering data management (MDM) system. 
Smart water metering (SWM): the integration of meter data into business systems (e.g., Billing System) and the sharing of information with customers (e.g., Customer Portal/Web).

Intelligent water networks (IWN): the integration of intelligent devices including water meters, pressure sensors, meter data, into all relevant business processes and systems and using this information to guide strategy and investment.

A few respondents felt that there remains room for improvement, with some suggesting to separate the system into its components (e.g., meter, sensor/pulse, data loggers/transmitters, network communications and ultimate data application/use). It was a strongly held belief by most respondents that there is an urgent need to establish a unified agreement on these definitions to facilitate subsequent clarity and progress in standardizing smart metering protocols across the country. Other identified terms requiring definitions were Operating Protocol and Remote Metering Infrastructure (RMI). For the purposes of consistency for this study, the WSAA definitions were used in the survey and presentation of results.

\section{Results and Discussion}

\section{Survey Results}

In 2013, a total of 26 organizations completed the online survey and in 2014, a total of 49 businesses responded, of which around half were return respondents from the previous year. The results reported herein will generally refer to the most update information gained from the 2014 survey unless otherwise stated. The majority of respondents were managers or senior managers, with a background in engineering and in the areas of customer and billing or asset/network management. The results are grouped into the five main areas of the survey. Select verbatim customer responses are quoted in italics within the figures.

\section{$\underline{\text { Key business case drivers for pursuing smart metering technology }}$}

Respondents were asked to rank pre-existing business case drivers in order of priority, with the top 3 priorities in particular to be ranked as accurately as possible. Survey response data presented in Figure 3 illustrates the number of times each that predefined business case driver was selected as the top priority (dark shading) or as a top 3 priority (light shading). The data demonstrates that costs drivers (reducing non-revenue water, deferring infrastructure and reduced manual meter reads) were seen as higher priorities overall than customer service related business drivers (Figure 3). When asked, many of the respondents indicated that a 'success rating' for their business case drivers was not yet applicable, although there appeared a trend toward the business goals being at least on track, if not achieved or exceeded. This also related to the ease of which some drivers could be quantified compared to others. For example, reduced labor costs, increased accuracy of meter reads and demand forecasting knowledge were all reasonably easy to quantify (i.e. hours of reduced read time, identifying outdoor water use flow volumes more accurately). Case study example of these are provided later in this paper. In terms of the business drivers not being achieved or on track, the reasons were stated as primarily technical issues relating to the "wireless communications technology" and "transponder reliability issues". 


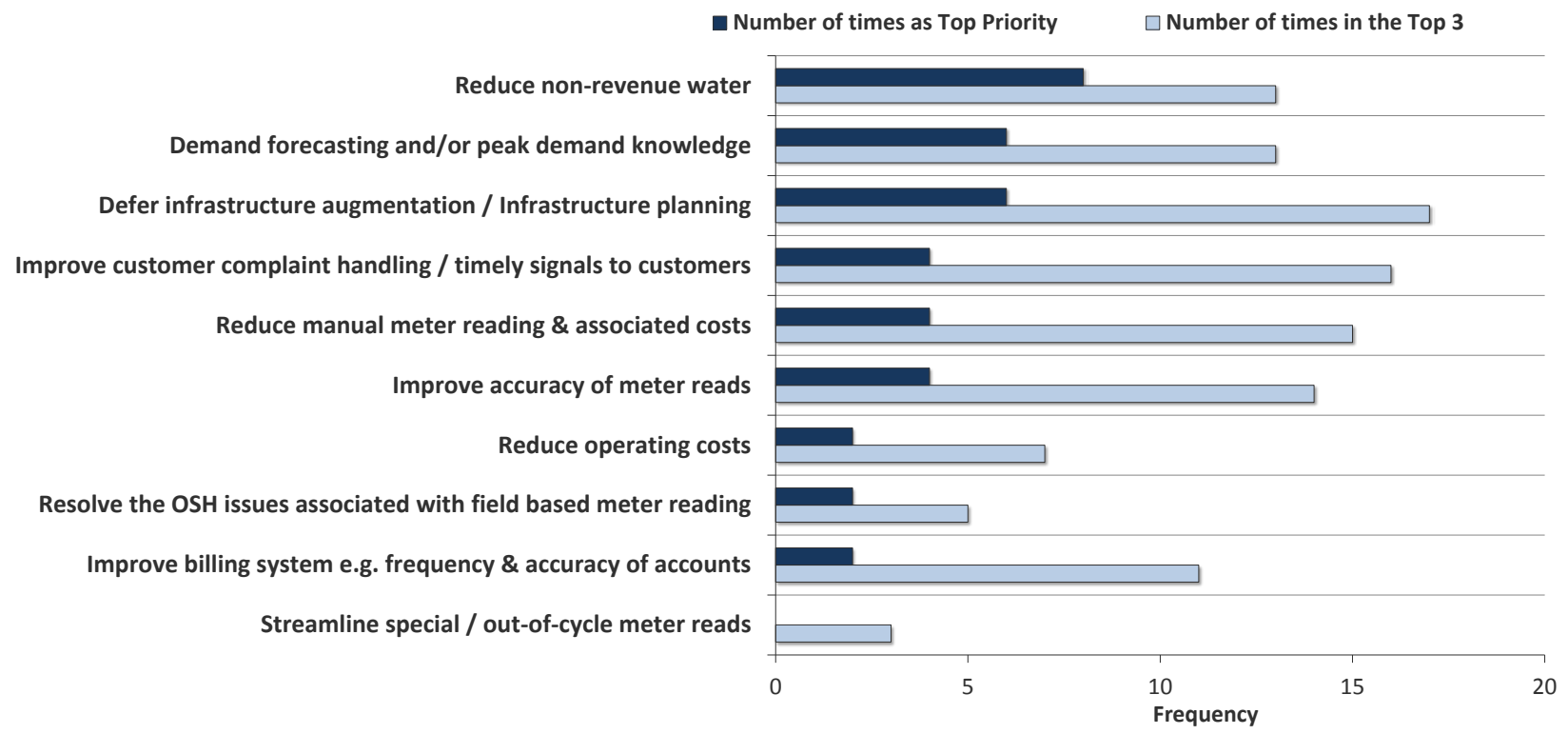

Figure 3. Priority ranked business case drivers for SW/IWN project implementation

\section{$\underline{\text { General overview of SM/IWN projects }}$}

A majority of survey respondents (78\%) were actively pursuing SM/IWN projects with $55 \%$ either currently in the rollout phase (46\%) or will be within 1 year (11\%). Of the "unsure" respondents (22\%) most were at the exploratory phase only, or had yet to determine the timing but had advanced the business case and technical scoping. Residential properties comprised $45 \%$ of project targets. Some projects focused on both commercial and residential properties, while others focused solely on high water users in the commercial sector (7 projects). Only two known projects are currently smart metering industrial water consumption.

Project costs ranged from $\$ 5,000$ to more than $\$ 15$ million dollars, depending on the scope of the project and the existing status of the system's meters (e.g., some areas were not even metered prior to the trial) (Table 1). Many utilities fully funded their projects, with some federal resources being the main source of supplementary funds. There were minimal discrepancies between the projected and actual project costs for completed projects. Given that unexpected costs and out-ofscope budget adjustments were commonly selected in the top 3 challenges during project rollout phases (discussed below), some water businesses still indicated that they had come under budget, although many were ongoing at the time of the survey. This further highlights that the benefits and limitations of such projects are very utility-specific and business cases are not a 'one-size fits all'. 
Table 1. Project funding and cost of selected respondents

\begin{tabular}{|c|c|c|}
\hline $\begin{array}{l}\text { Name of utility } \\
\text { or organisation }\end{array}$ & Project source funds & Project costs $^{1}$ \\
\hline $\begin{array}{c}\text { Western } \\
\text { Australia }\end{array}$ & Water utility and federal grant & $\$ 4 \mathrm{M}$ \\
\hline $\begin{array}{c}\text { North } \\
\text { Queensland }\end{array}$ & 100\% water utility & \$2.5M including AMI and MDM \\
\hline $\begin{array}{c}\text { South east } \\
\text { Queensland }\end{array}$ & 100\% water utility & \$150k \\
\hline $\begin{array}{c}\text { Western } \\
\text { Australia }\end{array}$ & $\begin{array}{c}\text { Initially self-funded via water connection charges (2000 } \\
\text { services installed 2007-10). Jointly funded 50/50 with } \\
\text { Federal Gov. 8,000 Services) }\end{array}$ & \$1.5M for Retrofit project \\
\hline Victoria & $100 \%$ water utility & $\$ 45 \mathrm{k}$ \\
\hline $\begin{array}{c}\text { South } \\
\text { Australia }\end{array}$ & Research & $\mathrm{n} / \mathrm{a}$ \\
\hline Tasmania & $\begin{array}{c}\text { Residential project - Jointly funded by Federal } \\
\text { Government under the National Urban Water Security } \\
\text { Plan for Cities and Towns. Costs for Residential Project } \\
\text { \$29.5M and \$5M from Federal Government }\end{array}$ & $\begin{array}{l}\text { Residential program - } \$ 29.5 \mathrm{M} \text {. Non- } \\
\text { Res project } \$ 6.5 \mathrm{M}\end{array}$ \\
\hline $\begin{array}{l}\text { South east } \\
\text { Queensland }\end{array}$ & $100 \%$ water utility & $100 \mathrm{k}$ \\
\hline Victoria & State, Commonwealth, water utility r & Estimate at this stage. \\
\hline $\begin{array}{c}\text { North } \\
\text { Queensland }\end{array}$ & Council and IBM & Est \$150k \\
\hline NSW & $\begin{array}{c}\text { Smart Grid, Smart City is a \$100M Australian } \\
\text { government funded project, led by Ausgrid and } \\
\text { supported by our consortium partners. }\end{array}$ & Meter cost and installation \\
\hline Victoria & To be determined & To be determined- $\$ 3-5 \mathrm{M}$ \\
\hline Victoria & 100\% water utility & Around $\$ 500 \mathrm{k}$ \\
\hline Victoria & $\begin{array}{l}\text { Joint fund DPI, water utility \& Farmers project approval } \\
\text { for } \$ 75 \mathrm{k}\end{array}$ & $\begin{array}{l}\text { \$120 per endpoint } 2 \text { TraNSWitters } \\
\text { @ \$6k each }\end{array}$ \\
\hline Victoria & Jointly funded by Water utility IWN program : 80/20 & $\$ 1 \mathrm{M}$ \\
\hline Victoria & 100\% water utility & Approximately \$40k \\
\hline NSW & $\begin{array}{c}\text { Water utility and schools - funding mix has varied } \\
\text { throughout program. }\end{array}$ & @\$100,000 spent to date \\
\hline NSW & $100 \%$ water utility & $\$ 400 \mathrm{k}$ \\
\hline NSW & $100 \%$ water utility & $\$ 76,365$ \\
\hline NSW & Council \& Taggle (meter company) & Unsure \\
\hline ACT & $100 \%$ water utility & $\begin{array}{l}\text { \$400k per year including monitoring } \\
\text { and maintenance }\end{array}$ \\
\hline
\end{tabular}

\section{$\underline{\text { Technology }}$}

The majority of respondents (51\%) were pursuing two-way communications (i.e., AMI or SWM per the definitions described earlier). Business-system integration and information sharing with customers (IWN) were applicable for $12 \%$ of the projects. The number of end points (i.e., meters, including sub-meters) ranged from less than 10 for a small pilot trial to more than 57,000 for a previously un-metered region of Tasmania. The median and average number of meters for the surveyed projects was approximately 300 and 7,000, respectively. Smaller projects with few end points typically were related to trial or pilot studies. 
Most respondents indicated that project meters recorded data at least hourly with the remainder typically opting for shorter read intervals ranging from 15 seconds to 30 minutes. Mobile phone networks were typically $3 \mathrm{G}$ or $4 \mathrm{G}$, but the majority of businesses had opted for either meshed or non-meshed low power radio frequency as their communication system. Several businesses chose to have aligned communications timing with their billing cycle. Daily communications of the logged usage back to the central system was the most popular method (39\%), with 6\% communicating back hourly. Respondents described a variety of meter data management systems. The option of developing or using their own in-house data management system was also popular. Additional meter capabilities included alarm systems (23\%) and remote configuration of the meter parameters by the utility, e.g. changing meter read interval (21\%).

Water utility's choices in primary communications network vendors were fairly evenly distributed although some of the communications network protocols were specific to the meter and data logger technology. This also applied to software vendors where several technology vendors had developed their own software program). Judging by the interest and extensive discussions at the 2013 and 2014 WSAA workshops regarding communication and software options, it is likely this area will be very 'organic' and rapidly evolving in the next few years as utilities become more aware of the options and applications of 'big data', and gain a more intimate knowledge of the options and processes involved in this quite complex component of the digital water space.

\section{$\underline{\text { Utility-customer relationships }}$}

Utilities were asked to describe their customer-engagement approach to rolling out their SM/IWN project. This is considered a crucial step, as without appropriate consultation with users, the benefits of smart meters, water conservation, and customer service-improvement are not likely to be realized. This will in turn reduce the likelihood of optimal outcomes for utilities and customers alike. A number of customer engagement and recruitment strategies were adopted (Figure 4). Older media channels provided the more popular approaches (e.g., letter mails outs, community group events, and phone calls/door knocks). The nature of the community group consultation ranged quite markedly from meeting with a local farm group or setting up a shopping centre kiosk, to holding several structured workshops and information sessions for the public.

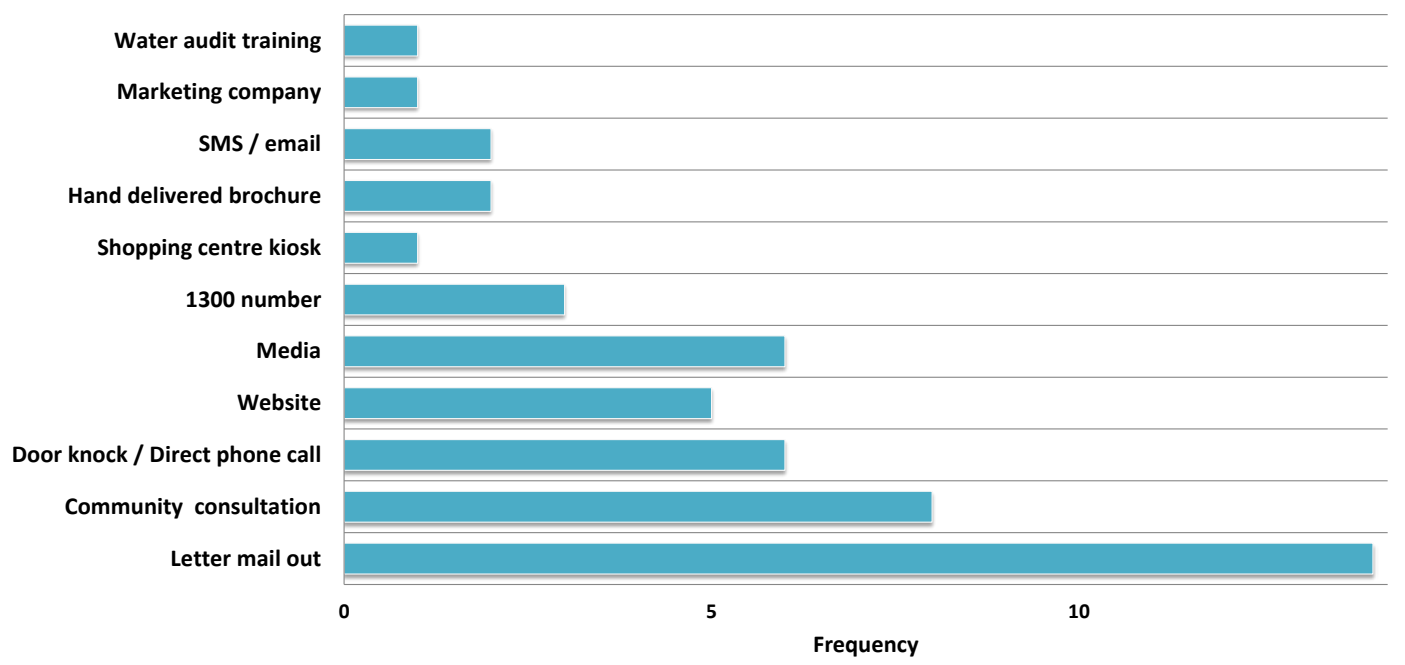

Figure 4. Type of customer-engagement strategies used 
Customer services and benefits from projects related primarily to post-meter leakage issues. Leakage alerts accounted for a quarter of the new services planned for SM/IWN projects, with several utilities also intending to use the smart metering data to develop benchmarking features on customer accounts. Some respondents (10\%) also indicated that they would offer a "self-service" feature, where customers are given access their data via a utility website at their choosing.

Leakage alerts frequency ranged from with a day to an approach dictated by leak severity. For those utilities intending to offer a leakage alert service, $66 \%$ were using or planned to use electronic methods of communications (e.g. SMS alert, smart app, web portal). This is in contrast with the engagement approach using 'traditional' methods (letters and phone calls). There appears to be a disconnect between methods of communicating the benefits of smart metering and the methods of implementing these benefits; consequently, some householders (such as the elderly) may be aware of the benefits of leak alerts, but may not be able to access this information if they are not IT “savvy.”

$\underline{\text { Key challenges and limitations for planning and implementing smart metering projects }}$

As with potential benefits, several implementation themes relating to challenges and limitations were identified by water utilities during the planning, design, and/or implementation phase of their projects. In the same survey question format as described for eliciting information on the priority business case drivers for utilities, respondents were asked to rank challenges and limitations of undertaking SM/IWN projects in order of priority. These were separated into the planning and operational phases, as challenges faced can be unique to each phase (Stewart et al. 2013).

\section{Planning Phase}

The planning phase top priorities centered around the lack of precedent showing a positive return on investment (ROI), positive outcomes and limited existing industry knowledge from previous smart metering projects (Figure 5). These issues featured both as top priorities (84\%) or were in the top 3 priorities (69\%) for a majority of utilities. It is likely that, over time, these will become lower priority limitations as more positive ROI evidence, case study outcomes and depth of knowledge of the overall management of the 'digital water age' become more apparent and widely documented. This point emphasizes the need for ongoing and relevant knowledge sharing through various fora (e.g. workshops, webinars) to establish and maintain a strong future in this rapidly growing area. Costs associated with the technology and rollout phases were also highlighted as a limitation, which is consistent with the issue of demonstrating a positive return on investment for high capital projects such as smart metering.

\section{Implementation / Rollout Phase}

The implementation or rollout phase priority challenges and limitations were a little less clear with the top priority responses not always aligning with the priorities frequently selected in the top 3 (Figure 6). For example, outdated technology and lack of knowledge and length of time to acquire suitable technology all featured strongly as top 3 priorities (combined $44 \%$ of sample) but were not often selected as the most critical challenge or limitation (combined $25 \%$ of sample). Limited industry knowledge and experience in rolling out smart metering was selected as the top priority challenge, comprising a quarter of the total responses, with the compatibility of metercommunication systems also featuring highly as a top priority challenge (Figure 6). Technical issues relating to the wireless communications technology were consistent reasons cited for project business case drivers not being achieved or not considered as 'on track' 


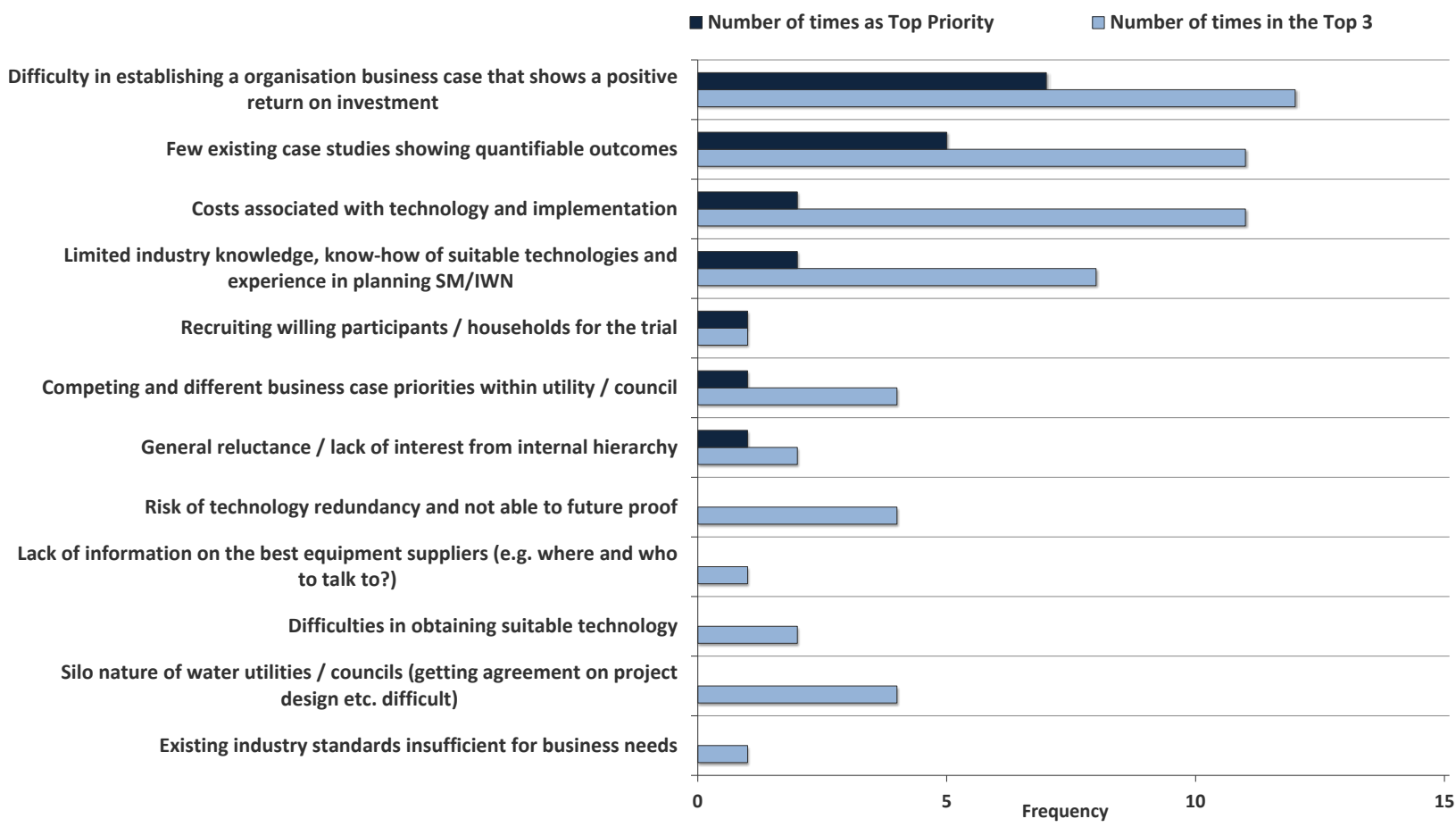

Figure 5. Priority ranked challenges and limitations during the planning stage of projects

Limited industry knowledge and experience in rolling out projects

Compatibility of meter-communication systems

Unexpected costs / out-of-scope budget adjustments

Difficulties with setting up and managing customer portal systems

Technology became quickly outdated

Lack of know-how of suitable technologies

Ongoing maintenance and operational difficulties that were not foreseen

Length of time to acquire, install and/or commission meters/loggers

Variability in walk/drive by signals

Issues with customer portal / data privacy

Number of times as Top Priority $\square$ Number of times in the Top 3
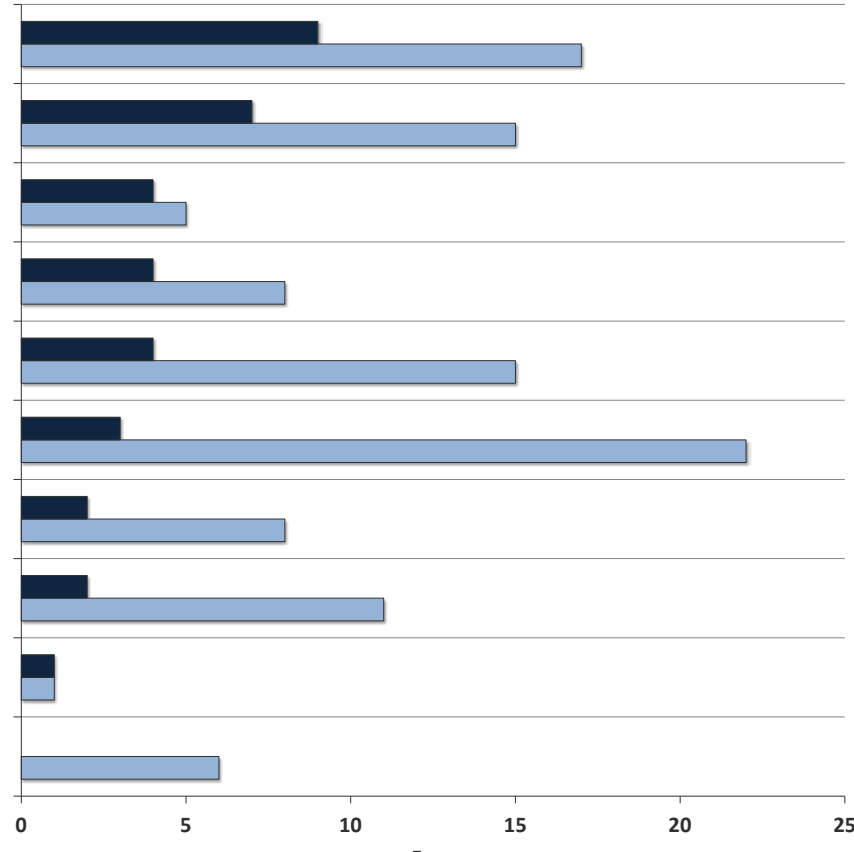

Figure 6. Priority ranked challenges and limitations during the implementation stage 


\section{Interview Results}

From all 49 water-business respondents, four of the largest projects were chosen for in-depth interviews in 2013 and follow up interviews in 2014 The water businesses of specific interest were Water Corporation of Western Australia (Kalgoorlie Smart Metering Trial), Mackay Regional Council, Queensland, TasWater (Southern Water at the time of the project) in Tasmania and City West Water, Victoria. These were selected as they represented water businesses that had completed a SM/IWN project, and could therefore provide some empirical insight about project benefits. Senior managers or project coordinators were chosen to be interviewed as they had the most intimate knowledge of their experience and had been central in developing the business case for their project. While it would have been ideal to have few more in-depth interviews with other respondents, most were in the early stages of a pilot study and would not have been able to provide the level of detail that was requested. As it was, the four organizations interviewed were somewhat limited in the level of information that they could access or release at the time due to inhouse protocols, but also due to a lack of across-silo data sharing.

The breakdown of key business case drivers for the four case studies are presented in the following tables. The chief purpose of the interviews was to capture some "real-life" examples of the benefits of SM/IWN projects. Project cost figures for the four cases (ranging from \$69 to \$531) are not an 'apples-with-apples' comparison because they have been calculated using different inclusions or exclusions of various costs based on the varying financial protocols of each water utility. Additionally, some of the case studies are focusing on multi-residential properties where sub-meters are required to be retrofitted and therefore not necessarily comparable to residential sites where existing end points are only upgraded. Nevertheless, the costs associated with each individual case study do provide a solid indication of the range of economic costs associated with smart meter roll outs.

Data in Table 2 indicates that reduction in operating costs, network upgrade deferment, increased accuracy and improved customer relations were key drivers for pursing projects. The case study interviewees all confirmed that not just one, but several factors had contributed to a strong business case, beyond purely economic drivers. Furthermore, the drivers tended to resonate across the silos in the utility or council (e.g. billing, customer service, asset management, demand management and planning). Thus, a successful business case tended to have not only a positive economic balance sheet but also captured other 'softer' benefits of digital water metering such as customer engagement and empowerment, integration of management systems across the business, perceived community water supply security and so on. It is noteworthy to add that the links between water and energy were more frequently discussed in 2014 compared to the 2013 review, with utilities acknowledging the benefits of water demand management translating into lower energy consumption and costs, for example reducing peak water demand can result in a reduction in energy use during peak electricity tariff times as shown by Beal et al. (2012).

There was an agreement from the interviewees, that a coordinated approach was needed to ensure technology was suitable for the desired outcomes, that is it was better to have a thorough understanding of the outcomes and goals of the project and then work backwards with technology selection, i.e. avoid the situation of the 'tail wagging the dog'. Choosing the right technology was generally considered to be only half the story as is was evident from survey results and subsequent interviews and workshop discussions that digital water technology is only as smart as the user and the user environment (e.g. communications network, software, storage and analytics). Additionally, there may not always be the need to get the "bells and whistles" technology, depending on the desired purpose of the data. If the purpose of the smart meter retrofit is to reduce 
manual read time and costs only, then an AMR system may be adequate. However, reflecting one of the themes of the 2014 survey; in light of the growing evidence demonstrating that an IWN system beyond just metering technology is likely to yield the most cost effective and efficient total water supply management plan, consideration needs to be given to the long-term application of digital water metering, thus ultimately, an AMI system may be more cost-effective. Therefore the planning and vision for how a digital water network can "work" for a utility is just as important as the technology itself.

The timing of utilities embarking on a SM/IWN was identified as a critical part of the likely success of the planning and rollout stages. For example, in one case, where there was available funding for the technology, the drive for change was simply not there, within the organization or some parts of the organization. The uncertainty around suitability and cost of technology, the failure to develop a strong business case and the presence of a significant spare capacity in water infrastructure (e.g. over-design for future peak demand was already addressed) were also reasons cited for prolonging smart water projects. 
Table 2. Case studies of smart metering projects in Australasia

\begin{tabular}{|c|c|c|c|c|}
\hline Description & Kalgoorlie Smart Metering Trial, & $\begin{array}{l}\text { Mackay real time water meter- } \\
\text { reading rollout }\end{array}$ & $\begin{array}{l}\text { Southern residential metering } \\
\text { project }\end{array}$ & $\begin{array}{l}\text { Multi-level development AMI } \\
\text { project }\end{array}$ \\
\hline $\begin{array}{l}\text { Utility and } \\
\text { location }\end{array}$ & $\begin{array}{l}\text { Water Corporation of Western } \\
\text { Australia }\end{array}$ & $\begin{array}{l}\text { Mackay Regional Council, } \\
\text { Queensland }\end{array}$ & TasWater, Tasmania & City West Water, Victoria \\
\hline Time period & $2010-2012$ & Ongoing roll out from 2010 & $2011-2012$ & Ongoing roll out from 2012 \\
\hline Technology & $\begin{array}{l}\text { AMI meters - Itron meters with } \\
\text { Everblu Wireless data system }\end{array}$ & $\begin{array}{lll}\text { AMI technology applied } & \text { (Elster } \\
\text { meters } \& \text { Taggle system) } & \\
\end{array}$ & $\begin{array}{l}\text { AMR technology applied } \\
\text { (Elster meters \& Coronis) }\end{array}$ & AMR and AMI (Everblu) \\
\hline $\begin{array}{l}\text { Number of end- } \\
\text { points (meters) }\end{array}$ & 13,800 end points & $\begin{array}{l}36,000 \text { end-points (currently about } \\
12,000 \text { ) }\end{array}$ & $\begin{array}{l}\text { 55,500+ residential meters and } \\
\text { 2,600 non-residential meters }\end{array}$ & 5,000 multi-residential \\
\hline Costs & $\begin{array}{l}\text { AUD \$4M project cost (self-funded + } \\
\text { federal grant) }\end{array}$ & AUD \$2.5M (wholly self-funded) & $\begin{array}{l}\text { \$29.5M residential and } \$ 6.5 \mathrm{M} \\
\text { non-residential (wholly self- } \\
\text { funded) }\end{array}$ & $\$ 45,000$ (wholly self-funded) \\
\hline $\begin{array}{l}\text { Business case } \\
\text { drivers }\end{array}$ & $\begin{array}{l}\text { - Reduce operating costs } \\
\text { - Improve occupational health \& } \\
\text { safety issues } \\
\text { - Reduce manual meter reading costs }\end{array}$ & $\begin{array}{l}\text { - Deferring augmentation } \\
\text { investments } \\
\text { - Improved customer knowledge and } \\
\text { relations } \\
\text { - Enhanced knowledge of network } \\
\text { operation }\end{array}$ & $\begin{array}{l}\text { - Improve accuracy of meter } \\
\text { reads } \\
\text { - Deferring augmentation } \\
\text { investments } \\
\text { - Improve customer equity } \\
\text { and relations } \\
\end{array}$ & $\begin{array}{l}\text { - Improve accuracy of meter } \\
\text { reads } \\
\text { - Improve leak detection and } \\
\text { - Reduce operating costs and } \\
\text { customer complaints/inequities }\end{array}$ \\
\hline $\begin{array}{l}\text { Key benefits of } \\
\text { project to date }\end{array}$ & $\begin{array}{l}\text { - } \$ 3 \text { M saving of water supplied by } \\
\text { - } \text { WMI } \\
\text { by almost } 834 \mathrm{ML} \text { (> } 10 \% \\
\text { reduction) } \\
\text { - Residential water use was reduced } \\
\text { by } 11 \% \text { to } 310 \mathrm{~kL} / \text { year in } 2011-12 \text {. } \\
\text { - Reducing field incidents of meter } \\
\text { reads and improving safety of field } \\
\text { officers. } \\
\text { - Residential leak reduction } \\
\end{array}$ & $\begin{array}{l}\text { - By reducing monthly peak demand } \\
\text { by } 10 \% \text {, the utility can defer } \\
\$ 100 \mathrm{M} \text { infrastructure for } 4 \text { years, } \\
\text { representing savings of } \$ 20 \mathrm{M} N \mathrm{NV} \\
\text { - Leak notifications have been issued } \\
\text { to clients in last } 2 \text { years - } \\
\sim 400 / \text { month at average volume of } \\
30 \mathrm{~L} / \mathrm{hr} \\
\text { - Customer portal software soon to } \\
\text { be user-tested. }\end{array}$ & $\begin{array}{l}\text { - Bulk water reduced by over } \\
3 \text { GL } \\
\text { - Deferring \$20M WTP } \\
\text { upgrade for } 7 \text { years, } \\
\text { representing capital } \\
\text { efficiency savings of \$7.9M. } \\
\text { - Deferring \$5M pipeline } \\
\text { upgrade for } 5 \text { years, } \\
\text { representing capital } \\
\text { efficiency savings of } \$ 1.6 \mathrm{M} \text {. }\end{array}$ & $\begin{array}{l}\text { Estimate \$45k annual savings } \\
\text { associated with improving } \\
\text { manual \& special read } \\
\text { efficiency } \\
\text { - Estimated \$89k savings in } \\
\text { future. } \\
\text { - Reduced customer queries and } \\
\text { complaints due to inaccurate } \\
\text { billing - from } 270 \text { to almost } \\
\text { none. }\end{array}$ \\
\hline $\begin{array}{l}\text { Key challenges } \\
\text { of project to } \\
\text { date }\end{array}$ & $\begin{array}{l}\text { - Few existing case studies showing } \\
\text { quantifiable outcomes } \\
\text { - Best approach to analyzing and } \\
\text { applying analytics of various data } \\
\text { sets }\end{array}$ & $\begin{array}{l}\text { - Length of time to acquire, install } \\
\text { and commission technology } \\
\text { - Compatibility of meter- } \\
\text { communication systems }\end{array}$ & $\begin{array}{l}\text { - Risk of technology } \\
\text { redundancy } \\
\text { - Costs associated with } \\
\text { technology and } \\
\text { implementation } \\
\end{array}$ & $\begin{array}{l}\text { - Risk of technology redundancy } \\
\text { - Compatibility of meter- } \\
\text { communication systems }\end{array}$ \\
\hline
\end{tabular}

Notes: WTP - water treatment plant; kL = kilolitres; GL = gigalitres 
A strong theme that emerged from the survey responses and case study interviews, was the customer focus and the benefits to the customer that digital water networks could deliver. Nevertheless, interview discussions revealed that the eagerness of utilities to engage customers has to be matched with the customers own understanding and willingness to participate, in order for the benefits of smart metering to be realized. For example, the lack of uptake from customers to engage in using the web portal, responding to SMS texts regarding leaks, modify behaviour based on feedback on high water use, and generally engage with the two-way process that SWM/IWN can offer. Therefore, it appears that in order to fully maximize the benefits of SWM/IWN to the customer (thus also to the utility), the project long-term goals must offer services that the customer actually wants or needs, not just what the utility thinks that the customer might want or need, thus a genuine consultation stage will be crucial to achieve this.

\section{Discussion and conclusions}

As for many developed countries across the globe, smart metering and intelligent water networks are gaining momentum within Australian water utilities as a viable alternative to traditional metering, and are not seen as just "a vision for the future". Worthington and Higgs (2014) state that the main cost advantage at all levels of Australian water business output (e.g. CAPEX and OPEX) is reducing water losses. There is strong evidence emerging from the larger water businesses that have pursued SM and IWN projects, that this cost advantage can be realized through the implementation of smart metering projects. This paper aimed to provide a snapshot of the current state of play for smart-metering projects in Australia by summarizing recent national surveys of water utilities on this issue.

With two thirds of the surveyed water utilities in either planning or operational phases of a smartmetering trial $(n>250,000)$, there appears momentum and traction in Australia for further uptake of SM/IWN projects. It seems a reasonable conclusion that it is an issue of when, not if, water providers will introduce some level of smart-metering capability in their network system. For a majority of respondents, there was little question about the benefits of smart metering, and financial constraints considered, uncertainly lies more with the type, timing, and technology of implementing these programs. Our findings suggest that key business drivers were easier to quantify and justify in terms of economics (benefits relative to costs) rather than customer engagement and satisfaction.. Key benefits identified were: savings in operating costs, reductions in bulk water supplied, deferred augmentation of infrastructure, increased revenues from more efficient meter reads, improved customer relations and reductions in non-revenue water losses.

The social benefits of customer satisfaction, community acceptance and improved customer engagement and trust are difficult to quantify, but interestingly, all respondents and interviewees identified this as either a direct on non-direct benefit of smart-metering projects. However, there was an absence of environmental drivers from a majority of water businesses. Although environmental benefits were sometimes implicit in the water savings accounting, it was rarely nominated explicitly as a business-case factor.

SM and IWN technology must address variable business and site-specific challenges and limitations. There is a limited knowledge of the capabilities of current and future technology in the smart-metering space for the water sector. The field is still young in this sense and a consistent issue identified was the lack of knowledge and expertise in designing and implementing large $\mathrm{SM} / \mathrm{IWN}$ projects. In some cases, there were well-financed projects without the capacity for implementation due to incompatibilities with meter/data storage/communication systems. This is 
especially so in regional areas as communication technology can be impeded by unreliable transmission signals (e.g. 3G and 4G still not available in some remote regions of Australia).

Each water business must understand their business goals. Developing a business case for smart metering must start with the organization's strategic drivers. What are the key problems facing your utility? What are the priority challenges that need to be addressed? What strategic initiatives are being pursued? The value of smart metering and the specific business case drivers are highly contextual to location. For example, in a location where the population is steady and capital expenditures have been significant (i.e., with capacity planned for growth), deferment of augmentation and infrastructure upgrades is unlikely to gain much traction. Improving operations and optimizing billing and maintenance programs, however, present opportunities for increasing reducing operating costs and increasing revenues. Conversely, in an area of high growth projection and existing infrastructure at a threshold capacity, deferring upgrades due to reduction in peak is a key driver.

Importantly, as noted by many of the survey respondents, establishing a standardized set of definitions relating to smart-metering technology is critical. Most organizations had their own definitions, but they only occasionally reflected those published nationally. Agreement on definitions is thus one of the first areas to be addressed if a national approach to smart water metering is to be undertaken.

Finally, the benefits of digital water network beyond just a smart water meter was clearly being recognized by utilities and this appears to be included as an important factor in many business cases. However, considering all the points mentioned above, this was not always recognized by the financial departments or other managers across a water business, or indeed the customer. Therefore communicating the benefits of investing in digital water technology needs to take on a coordinated approach across departments within businesses.

\section{Acknowledgements}

This study was a collaborative project between the Smart Water Research Centre at Griffith University and the Water Services Association of Australia (WSAA). The authors would like to thank WSAA for providing the funding and strong support for both the 2013 and 2013 online surveys, along with all the survey participants and interviewees.

\section{References}

Beal, C.D., Stewart, RA., Giurco, D., Panuwatwanich, K., (2014). Intelligent Metering for Urban Water Planning and Management. In K. Adeyeye (Ed.), Water Efficiency in Buildings: Theory and Practice (pp. 129-145): John Wiley \& Sons Ltd, UK.

Beal, C.D and Flynn, J. (2014) The 2014 Review of Smart Metering and Intelligent Water Networks in Australia and New Zealand. Report prepared for WSAA by the Smart Water Research Centre, Griffith University, November, 2014.

Beal, C.D and Flynn, J. (2013) Australian Review of Smart Metering and Intelligent Water Networks. Report prepared for WSAA by the Smart Water Research Centre, Griffith University, September, 2013.

Beal, C.D., Stewart, R.A., Bertone, E (2012) Evaluating the energy and carbon reductions 
resulting from resource-efficient household stock. Energy and Buildings, 55: 422-432.

NWC (2013) National Performance Report 2011-2012: urban water utilities. National Water Commission, March 2013 http://www.nwc.gov.au/_data/assets/pdf_file/0019/29170/Urban.pdf.

Little and Flynn (2012) Big Data, Smart Meters \& Australian Water Utilities: Insights from the Australian Water Utility Strategic Round Tables, conducted nationally June 25 to 28, 2012. Report prepared by the Smart Water Research Centre, Griffith University and Joe Flynn and Associates, July 2012.

Stewart, RA., Giurco, D., Beal, C.D. (2013) Age of intelligent metering and big data: Hydroinformatics challenges and opportunities. Journal of the International Association for Hydro-environment Engineering and Research, 2, 107-110. (2013).

Stewart, R., Willis, R., Giurco. D., Panuwatwanich, K., \& Capati, G. (2010) Web based knowledge management system: linking smart metering to the future of urban water planning. Australian Planner 2010; 47: 66 - 74.

Worthington, A.C. and Higgs, H. (2014) Economies of scale and scope in Australian urban water utilities. Utilities Policy 31(0), 52-62.

WSAA (2010) Domestic Smart Water Meter Specification. Water Services Association of Australia, December 2010. 